\title{
Improving Concentration and Mindfulness in Learning through Meditation
}

\author{
Dr Dalvinder Singh Grewal \\ Dean $R \& D$ Desh Bhagat University
}

\begin{abstract}
Meditation refers to a family of self-regulation practices that focus on training attention and awareness in order to bring mental processes under greater voluntary control and thereby foster general mental well-being and self-inducement of a mode of consciousness development whereby specific capacities such as calm, clarity, and concentration are attained. The process of concentrating, especially the fixing of close, undivided attention is the ability to direct one's thinking in whatever direction one would intend. Learning is the process of acquisition of knowledge which can be obtained through mindful learning. Mindfulness directs the power of concentration. Mindfulness is the manager of the operation. Concentration furnishes the power by which mindfulness can penetrate into the deepest level of the mind. Their cooperation results in insight and understanding. These must be cultivated together in a balanced ratio. Just a bit more emphasis is given to mindfulness because mindfulness is the center of meditation. Meditation helps concentration and mindfulness and; concentration and mindfulness help better learning. This paper concentrates on how effective meditation improves concentration and mindfulness for effective learning.
\end{abstract}

Keywords: Meditation, concentration, mindfulness, learning

Learning

\section{Introduction}

Learning is the process of acquisition of knowledge. The right knowledge can only be obtained through concentrated and mindful learning. Generally we hear the students saying: "I can't concentrate." "My mind wanders when I try to study." Lack of concentration is one of the most frequent complaints heard on a college campus. Concentrated learning involves tuning mind to the new requirement in a natural manner. Meditation is generally an internal, personal practice and done without any external involvement, except perhaps prayer beads to count prayers. There are dozens or more specific styles of meditation practice. In meditation the regulation of attention whether through concentration or mindfulness, is the central commonality or invariant ingredient in every meditation system. In popular usage, the word "meditation" and the phrase "meditative practice" are often used imprecisely to designate broadly similar practices, or sets of practices, that are found across many cultures and traditions. Meditation helps concentration and mindfulness; concentration and mindfulness help better learning.

\section{Concentration}

The act or process of concentrating, especially the fixing of close, undivided attention; ${ }^{1}$ concentration is the ability to direct one's thinking in whatever direction one would intend. ${ }^{2}$ Practically speaking, if you focus the rays of the sun through a lens, they can burn cotton or a piece of paper; but, the scattered rays cannot do this act. If you want to talk to a man at a distance you make a funnel of your hand and speak. The sound-waves are collected at one point and then directed towards the man. He can hear your speech very clearly. The water is converted into steam and the steam is concentrated at a point. The railway engine moves. All these are instances of concentrated waves. Even so, if you collect the dissipated rays of the mind and focus them at a point, you will have wonderful concentration. The concentrated mind will serve as a potent searchlight to find out the treasures of the soul and attain the supreme wealth of Atman (the Self), eternal bliss, immortality and perennial joy. Concentrated learning has made the people to remember whole book and recite it backwards.

We all have the ability to concentrate. Think of the times when you were engrossed in a super novel; while playing your guitar or piano; in an especially good game of cards; at a spellbinder of a movie, you have total concentration. But at other times when you sit for studies on are in a class, your thoughts are scattered, and your mind races from one thing to another. It is for those times that you need to learn and practice concentration strategies. They involve (1) learning mental self regulation and (2) arranging factors that you can immediately control. Improving concentration is learning a skill. Learning a skill takes practice; whether it is shooting baskets, dancing, typing, writing, or concentrating in a classroom.

Concentration could be defined as that faculty of the mind which focuses single mindedly on one object without interruption. It must be emphasized that true concentration is a wholesome one-pointedness of mind. 
That is, the state is free from all outwardly attractions and detractions. e.g., greed, hatred and delusion. Unwholesome one-pointedness is also possible, but it will not lead to liberation. You can be very single-minded in a state of lust. But that gets you nowhere. Uninterrupted focus on something that you hate does not help you at all. In fact, such unwholesome concentration is fairly short-lived even when it is achieved - especially when it is used to harm others. True concentration itself is free from such contaminants. It is a state in which the mind is gathered together and thus gains power and intensity. We might use the analogy of a lens. Parallel waves of sunlight falling on a piece of paper will do no more than warm the surface. But the same amount of light, when focused through a lens, falls on a single point and the paper bursts into flames. Concentration is the lens. It produces the burning intensity necessary to see into the deeper reaches of the mind. Mindfulness selects the object that the lens will focus on and looks through the lens to see what is there.

Concentration strategies require practice. You probably will begin to notice some change within a few days. You will notice considerable improvement within four to six weeks of training your mind with some of the skills that follow. And that is a short period of time considering how many years you have spent not concentrating as well as you would like.

Once a Sanskrit scholar approached Kabir and asked him, "O Kabir, what are you doing now?". Kabir replied, "O Pundit, I am detaching the mind from worldly objects and attaching it to the lotus-feet of the Lord". This is concentration.

Concentration is centering the mind on one single thought. A student concentrates on the material he is required to study; a teacher concentrate on the learning of subject he has to teach; a principal has to concentrate on finding the solution of the problems his institution is facing; a house wife requires to concentrate on cooking. Everybody possesses some ability to concentrate. Everybody does concentrate to a certain extent when he reads a book, when he writes a letter, when he plays tennis, and in fact, when he does any kind of work. Concentration is thus a great necessity for all aspirants.

When you study a book with profound interest, you do not hear if a man shouts and calls you by your name. You do not see a person when he stands in front of you. You do not smell the sweet fragrance of flowers that are placed on the table by your side. This is concentration or one-pointedness of mind. The mind is fixed firmly on one thing.

Those who practise concentration evolve quickly. They can do any work with scientific accuracy and great efficiency. What others read in six hours can be read, by one who does concentration, within half an hour. Concentration purifies and calms the surging emotions, strengthens the current of thought, and clarifies the ideas.

Concentration helps a man in material progress also. A person with good concentration will have a very good out-turn of work in his office or business house. He who practises concentration will possess very clear mental vision. What was cloudy and hazy before; becomes clear and definite now. What was difficult before becomes easy now. And what was complex, bewildering, and confusing before comes easily within the mental grasp. You can achieve anything through concentration. Nothing is impossible to a man who practises regular concentration.

It helps the scientists and professors to do great research work. It helps the doctor and the lawyer to do much work and earn more money. It develops will-power and memory; it sharpens and brightens the intellect. Concentration bestows serenity or calmness of mind, inner spiritual strength, patience, great capacity to turn out tremendous work, alacrity, acumen, agility, beautiful complexion, sweet voice, brilliant eyes, powerful voice and speech, power to influence others and attract people, cheerfulness, joy, bliss of soul and supreme peace. It removes restlessness, agitation of mind and laziness. It makes you fearless and unattached. It helps you to attain God- realisation. The more is the mind fixed on God the more is the strength you will acquire. More concentration means more energy. Concentration opens the inner chambers of love or the realm of eternity. Concentration is a source of spiritual strength. Be slow and steady in concentration. By practice of concentration, you will become superhuman. During concentration, the various rays of the mind are collected and focussed on the object of concentration. There will be no tossing of the mind. One idea occupies the mind. The whole energy of the mind is concentrated on that one idea. The senses become still. They do not function. When there is deep concentration, there is no consciousness of the body and surroundings.

Those who practise concentration off and on will have a steady mind only occasionally. Sometimes the mind will begin to wander and will be quite unfit for application. You must have a mind that will obey you at all times sincerely and carry out all your commands in the best possible manner at any time. Steady and systematic practice of meditation through yoga will make the mind very obedient and faithful. You will be successful in every attempt. You will never meet with failure. You will remember what you read. Really deep concentration can only take place under certain specific conditions. A college or school is a controlled environment where emotional noise and outer disbursements are kept to a minimum. 


\section{Mindfulness \& Concentration}

Mindfulness is a broader and larger function than concentration. It is an all-encompassing function. Concentration is exclusive. It settles down on one item and ignores everything else. Mindfulness is inclusive. It stands back from the focus of attention and watches with a broad focus, quick to notice any change that occurs. If you have focused the mind on a stone, concentration will see only the stone. Mindfulness stands back from this process, aware of the stone, aware of the concentration focusing on the stone, aware of the intensity of that focus and instantly aware of the shift of attention when concentration is distracted. It is mindfulness which notices the distraction which has occurred, and it is mindfulness which redirects the attention to the stone. Mindfulness is more difficult to cultivate than concentration because it is a deeper-reaching function. Concentration is merely focusing of the mind, rather like a laser beam. It has the power to burn its way deep into the mind and illuminate what is there. But it does not understand what it sees. Mindfulness can examine the mechanics of selfishness and understand what it sees. Mindfulness can pierce the mystery of suffering and the mechanism of discomfort. Mindfulness can make you free.

In a state of mindfulness, you see yourself exactly as you are. You see your own selfish behavior. You see your own suffering. And you see how you create that suffering. You see how you hurt others. You pierce right through the layer of lies that you normally tell yourself and you see what is really there. Mindfulness leads to wisdom.

Mindfulness is not trying to achieve anything. It is just looking. Therefore, desire and aversion are not involved. Competition and struggle for achievement have no place in the process. Mindfulness does not aim at anything. It just sees whatever is already there.

Mindfulness is not dependent on any such particular circumstance, physical or otherwise. It is a pure noticing factor. Thus it is free to notice whatever comes up - lust, hatred, or noise. Mindfulness is not limited by any condition. It exists to some extent in every moment, in every circumstance that arises. Also, mindfulness has no fixed object of focus. It observes change. Thus it has an unlimited number of objects of attention. It just looks at whatever is passing through the mind and it does not categorize. Distractions and interruptions are noticed with the same amount of attention as the formal objects of meditation. In a state of pure mindfulness your attention just flows along with whatever changes are taking place in the mind.

Mindfulness does not react to what it sees. It just sees and understands. Mindfulness is the essence of patience. Therefore, whatever you see must be simply accepted, acknowledged and dispassionately observed. This is not easy, but it is utterly necessary. We are ignorant. We are selfish and greedy and boastful. We lust and we lie. These are facts. Mindfulness means seeing these facts and being patient with ourselves, accepting ourselves as we are. That goes against the grain. We don't want to accept. We want to deny it; or change it, or justify it. But acceptance is the essence of mindfulness. If we want to grow in mindfulness we must accept what mindfulness finds. It may be boredom, irritation, or fear. It may be weakness, inadequacy, or faults. Whatever it is, that is the way we are. That is what is re al. Mindfulness simply accepts whatever is there. If you want to grow in mindfulness, patient acceptance is the only route. Mindfulness grows only one way: by continuous practice of mindfulness, by simply trying to be mindful, and that means being patient. The process cannot be forced and it cannot be rushed. It proceeds at its own pace.

Concentration and mindfulness go hand-in-hand in the job of meditation. Mindfulness directs the power of concentration. Mindfulness is the manager of the operation. Concentration furnishes the power by which mindfulness can penetrate into the deepest level of the mind. Their cooperation results in insight and understanding. These must be cultivated together in a balanced ratio. Just a bit more emphasis is given to mindfulness because mindfulness is the center of meditation. The deepest levels of concentration are not really needed to do the job of liberation. Still, a balance is essential. Too much awareness without calm to balance it will result in a wildly over sensitized state. Too much concentration without a balancing ratio of awareness will result in the 'Stone Buddha' syndrome. The meditator gets so tranquilized that he sits there like a rock. Both of these are to be avoided.

Concentration and mindfulness are distinctly different functions. They each have their role to play in meditation and the relationship between them is definite and delicate. Concentration is often called onepointedness of mind. It consists of forcing the mind to remain on one static point. Concentration is pretty much a forced type of activity. It can be developed by force, by sheer unremitting willpower. And once developed, it retains some of that forced flavor. Mindfulness, on the other hand, is a delicate function leading to refined sensibilities. These two are partners in the job of meditation. Mindfulness is the sensitive one. He notices things. Concentration provides the power. He keeps the attention pinned down to one item. Ideally, mindfulness is in this relationship. Mindfulness picks the objects of attention, and notices when the attention has gone astray. Concentration does the actual work of holding the attention steady on that chosen object. If either of these partners is weak, your meditation goes astray.

You can't develop mindfulness by force. Active teeth gritting willpower will not do you any good at all. As a matter of fact, it will hinder progress. Mindfulness cannot be cultivated by struggle. It grows by realizing, 
by letting go, by just settling down in the moment and letting yourself get comfortable with whatever you are experiencing. This does not mean that mindfulness happens-all by itself; far from it. Energy is required; effort is required. But this effort is different from force. Mindfulness is cultivated by a gentle effort, by effortless effort. The meditator cultivates mindfulness by constantly reminding himself in a gentle way to maintain his awareness of whatever is happening right now. Persistence and a light touch are the secrets. Mindfulness is cultivated by constantly pulling oneself back to a state of awareness, gently.

Focussing on the present rather than letting the mind drift lowers the stress hormone cortisol as per Shamath Project at UC Devis. ${ }^{3}$ The ability to focus mental resources on immediate experience is an aspect of mindfulness, which can be improved by meditation training. ${ }^{4}$ High levels of cortisol, a hormone produced by the adrenal gland, are associated with physical or emotional stress. Prolonged release of the hormone contributes to wide-ranging, adverse effects on a number of physiological systems. The study found that at an individual level, there was a correlation between a high score for mindfulness and a low score in cortisol both before and after the retreat. Individuals whose mindfulness score increased after the retreat showed a decrease in cortisol. ${ }^{5}$

\section{Meditation}

The word 'meditate' stems from the Latin root meditatum, i.e. to ponder. The term meditation was introduced as a translation for Eastern spiritual practices, referred to as dhyāna in Buddhism and in Hinduism, which comes from the Sanskrit root dhyai, meaning to contemplate or meditate. The term "meditation" in English may also refer to practices from Islamic Sufism or other traditions such as Jewish Kabbalah and Christian Hesychasm. Meditation has been practiced since antiquity as a component of numerous religious traditions, especially in monastic settings. Since the 1960s, meditation has been the focus of increasing scientific research of uneven rigor and quality. In over 1,000 published research studies, various methods of meditation have been linked to changes in metabolism, blood pressure, brain activation, and other bodily processes. Meditation has been used in clinical settings as a method of stress and pain reduction and to develop one's mind. New Age meditations are often influenced by Eastern philosophy, mysticism, Yoga, Hinduism and Buddhism yet may contain some degree of Western influence. In the West, meditation found its mainstream roots through the social revolution of the 1960s and 1970s, when many of the youth of the day rebelled against traditional belief systems as a reaction against what some perceived as the failure of Christianity to provide spiritual and ethical guidance. New Age meditation as practiced by the early hippies is regarded for its techniques of blanking out the mind and releasing oneself from conscious thinking. This is often aided by repetitive chanting of a mantra, or focusing on an object

Many New Age groups combine yoga with meditation where the control of mind and breathing is said to be the highest yoga. In Zen Yoga, Aaron Hoopes talks of meditation as being an avenue to touching the spiritual nature that exists within each of us. The influential modern proponent of Hinduism who first introduced Eastern philosophy to the West in the late 19th century

According to Swami Vivekananda: Meditation has been laid stress upon by all religions. The meditative state of mind is declared by the Yogis to be the highest state in which the mind exists. When the mind is studying the external object, it gets identified with it, loses itself. To use the simile of the old Indian philosopher: the soul of man is like a piece of crystal, but it takes the colour of whatever is near it. Whatever the soul touches ... it has to take its colour. That is the difficulty. That constitutes the bondage.

\section{Modern Definitions}

According to R. Jevning, et al in "The physiology of meditation" Meditation refers to a family of selfregulation practices that focus on training attention and awareness in order to bring mental processes under greater voluntary control and thereby foster general mental well-being and self-inducement of a mode of consciousness development whereby specific capacities such as calm, clarity, and concentration are attained.

Walsh \& Shapiro define meditation... as a stylized mental technique... repetitively practiced for the purpose of attaining a subjective experience that is frequently described as very restful, silent, and of heightened alertness, often characterized as blissful.

\section{Criteria for meditation}

Bond \& others identified three main criteria as essential to any meditation practice:

- the use of a defined technique,

- logic relaxation, and

- a self-induced state/mode.

Other criteria deemed important [but not essential] involve 
- a state of psychophysical relaxation,

- the use of a self-focus skill or anchor,

- the presence of a state of suspension of logical thought processes,

- a religious/spiritual/philosophical context, or

- a state of mental silence.

\section{Types of Meditation}

- Concentrative mediation: A practitioner can focus intensively on one particular object

- Mindfulness meditation on all mental events that enter the field of awareness

- $\quad$ or both specific focal points and the field of awareness

\section{Meditation Practices For Increasing Mindfulness And Concentration}

The ability to focus mindfulness on the learning experience is an aspect of mindfulness, which can be improved by meditation. Vipassana meditation is something of a mental balancing act. You are going to be cultivating two separate qualities of the mind - mindfulness and concentration. Ideally these two work together as a team. They pull in tandem, so to speak. Therefore it is important to cultivate them side-by-side and in a balanced manner. If one of the factors is strengthened at the expense of the other, the balance of the mind is lost and meditation impossible.

In 2011, researchers from the University of Wisconsin demonstrated that daily meditation-like thought could shift frontal brain activity toward a pattern that is associated with what cognitive scientists call positive, approach-oriented emotional states — states that make us more likely to engage the world rather than to withdraw from it. ${ }^{6}$

Participants were instructed to relax with their eyes closed, focus on their breathing, and acknowledge and release any random thoughts that might arise. Then they had the option of receiving nine 30-minute meditation training sessions over the next five weeks. When they were tested a second time, their neural activation patterns had undergone a striking leftward shift in frontal asymmetry - even when their practice and training averaged only 5 to 16 minutes a day.

As little as five minutes a day of intense inactivity, and a happier outlook is yours for the taking. Give the student a project of his liking and balance is restored. But mindfulness goes beyond improving emotion regulation. An exercise in mindfulness can also help with that plague of modern existence: multitasking. Our attention is not infinite.. Multitasking is a persistent myth. What we really do is shift our attention rapidly from task to task. Two bad things happen as a result. We don't devote as much attention to any one thing, and we sacrifice the quality of our attention. When we are mindful, some of that attentional flightiness disappears as if of its own accord.

\section{Concentration practice through meditation}

It is easy to concentrate the mind on external objects. The mind has a natural tendency to go outwards. In the beginning stage of practice, you can concentrate on a black dot on the wall, a candle flame, a bright star, the moon, or any other object that is pleasing to the mind. The mind should be trained to concentrate on gross objects in the beginning; and later on, you can successfully concentrate on subtle objects and abstract ideas.

There is no concentration without something to rest the mind upon. Concentrate on anything that appeals to you as good or anything which the mind likes best. It is very difficult to fix the mind, in the beginning, on any object which the mind dislikes. Practise various sorts of concentration. This will train or discipline your mind wonderfully. Now concentrate on the Himalayas, a very great object. Then concentrate on mustard or a pinpoint. Now concentrate on a distant object. Then concentrate on a near object. Now concentrate on a colour, sound, touch, smell, or taste. Then concentrate on the 'tik-tik' of a watch. Concentrate on you book/diagram/subject again.

Here a simple exercise on concentration is suggested. Sit on any comfortable pose. Place a picture of your subject in front of you. Look at the picture/diagram/matter with a steady gaze. Then close your eyes and visualize the picture/diagram/matter in the centre of your heart or in the space between the eyebrows. When the picture fades out in your mental vision, open the eyes and gaze at the picture/diagram $/ \mathrm{matter}$ again. Close your eyes after a few seconds and repeat the process.

For a new learner, the practice of concentration is disgusting and tiring in the beginning. He has to cut new grooves in the mind and brain. After some months, he will get great interest in concentration. The vital point in concentration is to bring the mind to the same point or object again by limiting its movements in a small circle in the beginning. That is the main aim. A time will come when the mind will stick to one point alone. This is the fruit of your constant and protracted meditation. The joy is indescribable now.

Concentration will increase by lessening the number of thoughts. Certainly, it is an uphill work to reduce the number of thoughts. Just as you will have to take back with care your cloth that is fallen on a thorny plant by 
removing the thorns one by one slowly, so also, you will have to collect back with care and exertion the dissipated rays of the mind that are thrown over the sensual objects for very many years. In the beginning, it will tax you much. The task will be very unpleasant.

When you sit for prayers and meditation, never think of your office work. When you work in the office, never think of the child who is sick or of any other household work. When you take bath, do not think of games. When you sit for meals, do not think of the work that is pending in the office. When you sit for studies do not think of meals or games. You must train yourself to attend to the work on hand with perfect one- pointedness.

Pranayama, reduction of wants and activities, renunciation of objects, solitude, silence, discipline of the senses, annihilation of lust and greed, control of anger, non-mixing with undesirable persons, giving up of the newspaper habit and of visiting cinemas, all these pave a long way in increasing the power of concentration. You must try to be always cheerful and peaceful. Then only you will have concentration of mind. The practice of friendship with equals, compassion towards inferiors or distressed persons, complacency towards superiors or virtuous persons, and indifference towards sinners or wicked persons will produce cheerfulness or serenity and destroy hatred, jealousy, and dislike. Concentration will be quite easy for you then. Mere emotional bubbling for the time being out of sheer curiosity, or for attaining psychic powers, cannot bring any tangible result.

The initial stages of mental cultivation are especially delicate. Too much emphasis on mindfulness at this point will actually retard the development of concentration. When getting started in meditation, one of the first things you will notice is how incredibly active the mind really is. The Theravada tradition calls this phenomenon 'monkey mind'. The Tibetan tradition likens it to a waterfall of thought. If you emphasize the awareness function at this point, there will be so much to be aware of that concentration will be impossible. Don't get discouraged. This happens to everybody. And there is a simple solution. Put most of your effort into one-pointedness at the beginning. Just keep calling the attention from wandering over and over again; tough it out. A couple of months down the track and you will have developed concentration power. Then you can start pumping you energy into mindfulness. Do not, however, go so far with concentration that you find yourself going into a stupor.

Mindfulness still is the more important of the two components. It should be built as soon as you comfortably can do so. Mindfulness provides the needed foundation for the subsequent development of deeper concentration. Most blunders in this area of balance will correct themselves in time. Right concentration develops naturally in the wake of strong mindfulness. The more you develop the noticing factor, the quicker you will notice the distraction and the quicker you will pull out of it and return to the formal object of attention. The natural result is increased concentration. As concentration develops, it assists the development of mindfulness. The more concentration power you have, the less chance there is of launching off on a long chain of analysis about the distraction. You simply note the distraction and return your attention to where it is supposed to be.

Thus the two factors tend to balance and support each other's growth quite naturally. Just about the only rule you need to follow at this point is to put your effort on concentration at the beginning, until the monkey mind phenomenon has cooled down a bit. After that, emphasize mindfulness. If you find yourself getting frantic, emphasize concentration. If you find yourself going into a stupor, emphasize mindfulness. Overall, mindfulness is the one to emphasize.

Mindfulness guides your development in meditation because mindfulness has the ability to be aware of itself. It is mindfulness which will give you a perspective on your practice. Mindfulness will let you know how you are doing. But don't worry too much about that. This is not a race. You are not in competition with anybody, and there is no schedule.

One of the most difficult things to learn is that mindfulness is not dependent on any emotional or mental state. We have certain images of meditation. Meditation is something done in quiet caves by tranquil people who move slowly. Those are training conditions. Education institutions are such training grounds. They are set up to foster concentration and to learn the skill of mindfulness. Once you have learned that skill, however, you can dispense with the training restrictions, and you should. You don't need to move at a snail's pace to be mindful. You don't even need to be calm. You can be mindful while solving problems in intensive calculus. You can be mindful in the middle of a football scrimmage. You can even be mindful in the midst of a raging fury. Mental and physical activities are no bar to mindfulness. If you find your mind extremely active, then simply observe the nature and degree of that activity. It is just a part of the passing show within.

\section{Conclusion}

Concentration and mindfulness are essential for better learning. These are purely the mental process. One needs to control one's mind on to an object or reality. It is not a muscular exercise. There should be no undue strain on the brain. You should not fight and wrestle with the mind violently. When you concentrate on any object, avoid tension anywhere in the body or mind. Think gently of the object in a continuous manner. Do not allow the mind to wander away. Concentration can be done only if you are free from all distractions. A man whose mind is filled with passion and all sorts of fantastic desires can hardly concentrate on any object even for a second. His mind will be jumping like an old monkey. Too much physical exertion, too much talking, too 
much eating, too much mixing with the opposite sex and undesirable persons, too much walking, will cause distraction of mind. Those who practise concentration must abandon these things. Whatever you do, do with perfect concentration. Never leave it without finishing it completely. Meditation is the best method to help concentrate and mindfulness. You have select form of yoga according to your choice.

\section{References}

[1]. The American Heritage ${ }^{\circledR}$ Dictionary of the English Language, Fourth Edition copyright @2000 by Houghton Mifflin Company. Updated in 2009. Published by Houghton Mifflin Company.

[2]. http://www.k-state.edu/counseling/topics/career/concentr.html

[3]. Andy Fell/UC Davis News Service (2013) Mindfulness from meditation associated with stress hormone, Journal of Health Psychology, AM PDT

[4]. ibid

[5]. bid

[6]. Maria Konnikova (2013) "Mastermind: How to Think Like Sherlock Holmes" Columbia University. 